\title{
Degradation in Pharmaceutical Creams: Ascorbic Acid Demonstrating Phenomenon: A Review
}

\section{Safila Naveed ${ }^{*}$ and Sidra Sajid}

Jinnah University for Women, Karachi, Pakistan

\begin{abstract}
Background: Pharmaceutical preparations for topical use are available in semi-solid dosage form termed as creams, have tendency to degrade it or there are some factors involve in the phenomenon.

Aim: This review is compilation of studies performed on stability and degradation of Ascorbic acid (AA) creams by keeping goal in mind to finely demonstrate the central premise of this article that is to cover all aspects related to degradation in pharmaceutical creams. It was required to deep insight into degradation specifically in pharmaceutical creams, influences for phenomenon, degradation products, stability concerns and its effects on efficacy and safety of pharmaceutical creams.
\end{abstract}

Method: A literature survey was carried out using scientific websites for publications according to predetermined search sequence. Ascorbic acid cream was taken as model in few articles to illustrate relevant studies.

Result: Light, temperature, $\mathrm{pH}$, microbial contamination, incompatibility of active ingredient or excipients, closure and packing material are the influential factors that may led pharmaceutical creams towards instabilities or degradation.

Conclusion: This article concludes with the overview of published articles that there are certain factors of degradation in creams and by routine stability testing and adopting appropriate precautionary measures degradation in creams can be controlled and minimize.

Keywords: Creams; Degradation; Stability; Ascorbic acid

\section{Introduction}

Creams are defined as Semi-solid preparations for cutaneous application, intended for local or transdermal delivery of active substances, or for their emollient or protective action. They are of homogeneous appearance [1]. Creams are topical semi-solid dosage form, contain one or more active ingredients uniformly dispersed or completely dissolved in a specific base and suitable specific excipients such as, viscosity-enhancer agent, emulsifiers, antimicrobial agents, stabilizing agents and antioxidants [2]. Use of antimicrobial agent is quiet necessary in preparations that are more susceptible to the growth of microorganisms or unless product have itself some antimicrobial properties. Assurance must be provided through product sufficient preformulation studies that excipients do not interfere with availability of the active ingredient(s) and indicate suitable compatibility with other excipients of the dosage form.

Stability of a pharmaceutical product may be defined as the proficiency of any dosage form in a specific container/closure system to persist its physical, chemical, toxicological, microbiological specifications [3]. Stability of pharmaceutical preparations can also be affected due to microbiological changes like growth of microorganisms in non-sterile products and changes occurs in preservative efficacy [4]. Stability studies are useful in providing sufficient information that must be required in selection of acceptable formulations, excipients and packing material for under development product and to evaluate its shelf life and storage conditions. According to WHO, environment factors effects the stability of finished pharmaceutical products which include temperature, light, humidity .On the other hand nature and physicochemical properties of active ingredients and excipients also influence the stability of product. Manufacturing procedure, closure, container and packing material nature play an important role in maintaining the stability of preparations [5].
Selection of Ascorbic acid creams to illustrate the present study is due to reason that potential role of ascorbic acid as active ingredient in topical pharmaceutical preparations and cosmetics product is being stimulated wide [6-11]. Ascorbic acid is naturally occurring antioxidant, effective in treatment and prevention of photo aged skin [12] and helpful in skin depigmentation and collegen synthesis [13]. Chemical and photochemical oxidation are considered to be major cause of degradation in creams containing Ascorbic acid and also show sensitivity towards air and light [14-20]. L-dehydroascorbate (DHA) and 2,3-L-diketogulonate (2,3-DKG) , L-erythrulose (ERU) and oxalate are the primary degradation products of Ascorbic acid [21]. HPLC $[22,23]$ and GLC [24] were proposed method for determination of ascorbic acid degradation products.

\section{Types of Degradation in Creams}

- Photodegradation

- Degradation by heat

- Degradation by change in $\mathrm{pH}$

- Degradation by microbial contamination

- Degradation by formulation ingredients

${ }^{*}$ Corresponding author: Safila Naveed, Faculty of Pharmacy, Jinnah University for Women, Karachi, Pakistan, Tel: 00923002621917; E-mail: safila117@yahoo.com

Received November 25, 2015; Accepted January 15, 2016; Published January 22, 2016

Citation: Naveed S, Sajid S (2016) Degradation in Pharmaceutical Creams: Ascorbic Acid Demonstrating Phenomenon: A Review. J Bioequiv Availab 8: 080 083. doi: $10.4172 / \mathrm{jbb} .1000272$

Copyright: $\odot 2016$ Naveed S, et al. This is an open-access article distributed under the terms of the Creative Commons Attribution License, which permits unrestricted use, distribution, and reproduction in any medium, provided the original author and source are credited. 


\section{Evidence of degradation}

Visible change in consistency or appearance in dosage form like excessive "bleeding" (separation of excessive amounts of liquid) or formulation forms grittiness and agglomerates [2]. Other noticeable changes are:

- Change in color or discoloration

- Emulsion breakdown; Crystal formation

- Preparation shrinked due to evaporation of water

- Evidence of presence of microbial growth

- Change in odor is also a sign of instability

\section{Precautions}

- Avoid to form dilutions of topical semi solid dosage form until and unless it must require and care should be taken to use base of same type to obtain homogenous mixture.

- Creams should be of uniform consistency. No solid components should be observed when a cream is rubbed on the back of the hand.

- The container material must not interfere with product and affect the quality of the preparation or allow contamination of any type across the material of the container into the preparation. The closure must be well fitted to container and is equipped in such a way that tells whether the container has ever been opened or not.

- Packaging must be adequate to protect Topical semi-solid dosage forms, must be packed that it is prevented from light, humidity, and loss during handling and transportation. Mostly flexible metal tubes are used. Nasal, aural, vaginal, or rectal creams should be delivered in containers modified for suitable delivery of the product to the site of application, or along with proper applicator [2].

\section{Stability Testing Methods}

Stability testing is performed to determine the quantitative decrease in the amount of active ingredient in any dosage form due to degradation. Stability indicating methods are used to measure concentration of active ingredient accurately regardless of presence of impurities and interaction of excipients or degradation products $[25,26]$.

\section{Following are types of stability testing:}

\section{Real-time stability testing}

To get significant degradation in product under recommended storage conditions, real time stability test is performed; it is done for long period of time to achieve required degradation.

\section{Accelerated stability testing}

In accelerated stability testing, a product is subjected to different raised temperatures, warmer and ambient to accelerate degradation. Amount of heat that is supplied to make conditions required for product failure is than calculated.

\section{Retained sample stability testing}

In this testing one batch products are retained for at least 1 year and performed stability testing. This practice is required for usually every marketed product.

\section{Cyclic temperature stress testing}

In cyclic temperature stress testing, product being subjected to cyclic temperature stress on the basis of knowledge of product in order to create likely market place storage conditions. The cycle time is set as 24 hours according to diurnal rhythm on earth i.e. 24 hour. This testing is not considered as routine testing for marketed products but mostly products experienced such conditions during storage in market.

\section{Microbiological Spoilage in Pharmaceutical Creams and Cosmetics}

Major cause of microbiological spoilage in cream are bacteria, yeast or fungi which enormously affect their metabolic activities by making behavioral changes due to genetic alterations which lead to adaptations of wide range of environment conditions .Genetic mutation is also another cause of microbiological spoilage. Toiletry products, complex cosmetics of either usual ingredients or natural products including vitamins and animal proteins, come under this heading. These materials are highly succeseptible to microbial growth because of reason these provides sufficient nutrients to micro-organism, destroy activity of preservatives added and lead to contamination. Example of Klebsiella species was quoted in this article that this organism frequently produces gas in prolonged preserved products when subjected to use in cream and lotions [27].

Topical preparations may contain some level of microbial presence in which Staphylococci and other gram-positive cocci are more preeminent. These topical products have less capability of suppressing bacterial growth during usage and usually do not meet the microbial limits stated in official monographs. Microbial contamination adversely affects the stability of product [28].

Following are some significant changes occur in pharmaceutical creams and lotions due to microbial contamination.

$$
\begin{aligned}
& \text { - Altered activity } \\
& \text { - Visible growth } \\
& \text { - Gas production } \\
& \text { - Color changes } \\
& \text { - Change in texture and taste } \\
& \text { - Olfactory effects }
\end{aligned}
$$

\section{Effect of Temperature on Stability of Ascorbic Acid}

Temperature effect the stability of topical creams of different emulsified systems containing AA as active ingredient. In the presented article [29] author was by using non-ethoxylated, non-ionic skin compatible emulsifiers, Several $\mathrm{O} / \mathrm{W}$ micro emulsions, $\mathrm{O} / \mathrm{W}$ and $\mathrm{W} / \mathrm{O}$ emulsions and a $\mathrm{W} / \mathrm{O} / \mathrm{W}$ multiple emulsion were prepared. Ascorbic acid (vitamin C) was added to the emulsified systems and its stability against oxidation was observed at $45.0^{\circ} \mathrm{C}$ by providing aerobic conditions and compared with that in aqueous solutions at different $\mathrm{pH}$ values and observed all emulsified systems provided good protection to ascorbic acid, as its degradation rate, which dependent on increasing $\mathrm{pH}$, was slower in given emulsified systems than in aqueous solutions. Ascorbic acid showed highest protection when it was dissolved in aqueous phase of the $\mathrm{W} / \mathrm{O} / \mathrm{W}$ multiple emulsions, both at 45 and at $20^{\circ} \mathrm{C}$ storage for long period.

Rate of degradation in ascorbic acid product increased with increase in dry temperature. A study based on evaluation of degradation and its 
effects on nutritional quality of final product [30] is being included in this review article to summarize the effect of heat on Ascorbic acid. Author investigated degradation kinetics in ascorbic acid in tomatoes by providing different drying temperature. The degradation rates were dependent on samples drying temperature. Lower degradation rates were observed in osmotically pre-treated whole tomatoes, whereas higher degradation rates happened in halved tomatoes. Thus studies concluded ascorbic acid in tomatoes was degraded due to high temperature period.

\section{Formulation Characteristics Affecting Stability of Ascorbic Acid Cream}

Two derivatives of AA, i.e., Ascorbyl palmitate and sodium ascorbyl phosphate, which differ in stability and hydro-lipophilic properties were studied by P Spiclin, M Gasperlin, V Kmetec in 2001. These are widely used in pharmaceutical and cosmetic preparations. In the present work [31] the stability of both derivatives were studied in two microemulsions for topical use as carrier systems. The micro emulsions were composed of the same ingredients and are of both types, i.e., o/w and w/o. Ascorbyl palmitate is a less stable derivative and it is tested by providing different conditions to assess the influence of initial concentration, dissolved oxygen, location in microemulsion and storage conditions. High concentrations of ascorbyl palmitate reduced the degree of its degradation. The location of ascorbyl palmitate in the microemulsion and oxygen dissolved in the system and the location of ascorbyl palmitate in the microemulsion combinely put an immense effect on the stability of the compound. Light accelerated the degradation of ascorbyl palmitate. Contrary, sodium ascorbyl phosphate was stable in both microemulsions type. Sodium ascorbyl phosphate was revealed to be convenient as an active ingredient in topical dosage form. In case of ascorbyl palmitate, long-term stability in selected microemulsions was not adequate. Hence to formulate an optimal carrier system for this ingredient other factors influencing the stability have to be considered.

Research made by (Sheraz et al.) will be helpful in this review article to understand the major formulation factors that could impact on stability of AA creams. Study [32] based on formulating different water-in-oil (w/o) creams of ascorbic acid (AA) as a strong topical or cosmetic preparation for use as anti-aging. The effect of medium $\mathrm{pH}$ and viscosity, use of different excipients on physicochemical stability of Ascorbic acid during storage was assessed. Several waterin-oil (w/o) cream formulations of AA were prepared at $\mathrm{pH}$ 4-6 using different humectants and emollients. Creams were placed in the dark at $30^{\circ} \mathrm{C}$ for a period of three months and stability studies for Ascorbic acid were made in order to check loss and change in physical features. Results reveals that $\mathrm{pH}$ of the creams appeared to influence the stability of $\mathrm{AA}$ as the degradation rate found to rise with rise in $\mathrm{pH}$ by firstorder kinetics. The stability of AA was improved as the viscosity of the medium increased. Creams that showed the highest rates of degradation (i.e., at $\mathrm{pH}$ 6) comparison were also performed with the creams at the same $\mathrm{pH}$ by adding citric acid $(\mathrm{CT})$ as a stabilizing agent. CT was found to responsible for decrease the rates of degradation of $\mathrm{AA}$ in all the formulations.

Another study [23] needed to add in this review article to describe the degradation of ascorbic acid into its degradation product in aqueous solution at different $\mathrm{pH}$ values. Four main degradation products of AA, furfural, 2-furoic acid, 3-hydroxy-2-pyrone, and an unidentified compound, were separated and determined by HPLC method after heated at $100^{\circ} \mathrm{C}$ for 2 hours. Ascorbic acid was converted to 2 -furoic acid and 3-hydroxy-2-pyrone in acid aqueous solution while furfural at very low $\mathrm{pH}$ (i.e., $\mathrm{pH}$ 1), In an alkaline aqueous solution, the unknown compound became the main degradation product of ascorbic acid and very small amounts of furfural and 3-hydroxy-2-pyrone with no 2 -furoic acid were noticed at $\mathrm{pH} 10$.Hence result revealed high $\mathrm{pH}$ values lead to more degradation in AA.

\section{Photolytic Degradation}

To describe the degradation kinetics in AA cream due to light, Ahmad I and companions in 2011 performed study [33] in which first order degradation rate was evaluated by using spectrophotometer with a reproducibility of $\pm 5 \%$. Dehydroascorbic acid and 2,3-diketogulonic acid were formed as a photolytic degradation product of AA. Viscosity, $\mathrm{pH}$, concentration of active ingredient were found to affect the photolysis in AA. Study indicated that redox potential, ionized form of AA and viscosity of humectant play an important role in photostability of the vitamin in cream formulations. Observation made that cream formulations kept in dark; AA is affected in same manner in presence of such factors and undergoes aerobic oxidation and ultimately photolytic reactions. Spectrophotometric results showed that the rate of oxidative degradation in presence of light is about seventy times faster than that observed in dark.

Next year 2012, Ahmad I performed another study on same topic, i.e., photostability of AA but at that time author also observed the effect of presence of 3 different stabilizers in o/w cream formulation that are citric acid (CT), tartaric acid (TA) and boric acid (BA). Cream formulations exposed to the UV light and few samples kept in dark. The outward first-order rate constants for degradation of AA were $(0.34-0.95 \times 10(-3) \min (-1)$ in light, $0.38-1.24 \times 10(-2)$ day $(-1)$ in dark) in the presence of the stabilizers. These rate constants were used to determine the second-order rate constants for the interaction of AA with stabilizers. Result revealed that stabilizers are useful in inhibition of the rate of degradation of AA samples both in the light and in the dark but the inhibitory effect of the stabilizers came in the order of $\mathrm{CT}>\mathrm{TA}>\mathrm{BA}$. The rate of degradation of $\mathrm{AA}$ in the presence of these stabilizers in dark is about 120 times slower than that in the light [34,35].

\section{Conclusion}

The literature explored to review degradation in pharmaceutical creams came with conclusion that these topical preparations degrade to different extent on exposure to temperature, light, microbiological contamination and formulation characteristics including $\mathrm{pH}$, viscosity and ingredients used in emulsion system. As result of combination of these factors pharmaceutical creams show complex behavior like formation of degradation products that may be toxic or nontoxic in nature, breakdown of creams bases, physical and chemical instability making preparations inappropriate for use. Hence this revealed the fact that by stepping towards pre and post formulation precautionary measures and substantial follow up of stability protocols testing lead to control degradation phenomenon and to achieve efficacy and safety of pharmaceutical topical creams.

\section{References}

1. (2008) British Pharmacopoeia Volume III Formulated Preparations: General Monographs.

2. (2006) Topical semi-solid dosage forms. The international pharmacopeia $4^{\text {th }}$ (Edn): 969. 
Citation: Naveed S, Sajid S (2016) Degradation in Pharmaceutical Creams: Ascorbic Acid Demonstrating Phenomenon: A Review. J Bioequiv Availab 8: 080-083. doi:10.4172/jbb.1000272

3. Kommanaboyina B, Rhodes CT (1999) Trends in stability testing, with emphasis on stability during distribution and storage. Drug Dev Ind Pharm 25: 857-868.

4. Matthews BR (1999) Regulatory aspects of stability testing in Europe. Drug Dev Ind Pharm 25: 831-856.

5. Kaur M, Kaur G, Kaur H, Sharma S (2013) Overview on stability studies. International Journal of Pharmaceutical Chemical and Biological Sciences 3: 1231-1241.

6. Gallarate M, Carlotti ME, Trotta M, Bovo S (1999) On the stability of ascorbic acid in emulsified systems for topical and cosmetic use. Int J Pharm 188: 233241

7. Raschke T, Koop U, Düsing HJ, Filbry A, Sauermann K, et al. (2004) Topical activity of ascorbic acid: fromin vitro optimization to in vivo efficacy. Skin Pharmacol Physiol 17: 200-206.

8. Placzek M, Gaube S, Kerkmann U, Gilbertz KP, Herzinger T, et al. (2005) Ultraviolet $\mathrm{B}$-induced DNA damage in human epidermis is modified by the antioxidants ascorbic acid and Dalpha- tocopherol. J Invest Dermatol 124: 304-307.

9. Lin FH, Lin JY, Gupta RD, Tournas JA, Burch JA, et al. (2005) Ferulic acid stabilizes a solution of vitamins $C$ and $E$ and doubles its photoprotection of skin. J Invest Dermatol 125: 826-832.

10. Heber GK, Markovic B, Hayes A (2006) An immunohistological study of anhydrous topical ascorbic acid compositions on ex vivo human skin. J Cosmet Dermatol 5: 150-156.

11. Nusgens BV, Humbert P, Rougier A, Colige AC, Haftek M, et al. (2001) Topically applied vitamin $C$ enhances the mRNA level of collagens I and III, their processing enzymes and tissue inhibitor of matrix metalloproteinase 1 in the human dermis. J Invest Dermatol 116: 853-859.

12. Nusgens BV, Humbert $P$, Rougier A, Colige AC, Haftek M, et al. (2001) Topically applied vitamin $C$ enhances the mRNA level of collagens I and III, their processing enzymes and tissue inhibitor of matrix metalloproteinase 1 in the human dermis. J Invest Dermatol 116: 853-859.

13. Farris PK (2005) Topical vitamin C: a useful agent for treating photoaging and other dermatologic conditions. Dermatologic surgery 31: 814-818.

14. British Pharmacopoeia (2009) London: Her Majesty's Stationary Office. Electronic version.

15. Blaug SM, Hajratwala B (1972) Kinetics of aerobic oxidation of ascorbic acid. J Pharm Sci 61: 556-562

16. Silva E, Quina FH (2006) Photoinduced processes in the eye lens: do flavins really play a role. In: Silva E, Edwards AM (Eds). Flavins photochemistry and photobiology. Cambridge: The Royal Society of Chemistry. Chapter 7.

17. Vaid FHM, Shaikh RH, Ansari IA, Ahmad I (2005) Spectral study of the photolysis of aqueous thiamine hydrochloride and ascorbic acid solution in the presence and absence of riboflavin. J Chem Soc Pak 27: 227-232.

18. Vaid FHM, Shaikh RH, Ansari IA, Ahmad I (2006) Chromatographic study of the photolysis of aqueous thiamine hydrochloride and ascorbic acid solutions in the presence and absence of riboflavin. J Chem Soc Pak 28: 464-481.
19. Ahmad I, Sheraz MA, Shaikh RH, Ahmed S, Vaid FHM, et al. (2010) Photostability of ascorbic acid in aqueous and organic solvents. J Pharm Res 3: $1237-1239$

20. Sheraz MA, Ahmed S, Ahmad I, Qadeer K, Vaid FHM (2010) Photodegradation and photostabilization of ascorbic acid in pharmaceutical preparations. Int $J$ Chem Anal Sci 1: 68-70.

21. Sheraz MA, Ahmed S, Ahmad I, Vaid FHM, Iqbal K (2011) Formulation and stability of ascorbic acid in topical preparations. System Rev Pharm 2: 86-90.

22. Simpson GL, Ortwerth BJ (2000) The non-oxidative degradation of ascorbic acid at physiological conditions. Biochim Biophys Acta 1501: 12-24.

23. Nováková L, Solich P, Solichová D (2008) HPLC methods for simultaneous determination of ascorbic and dehydroascorbic acids. TrAC Trends in Analytical Chemistry 27: 942-958.

24. Yuan JP, Chen F (1998) Degradation of ascorbic acid in aqueous solution Journal of Agricultural and Food Chemistry 46: 5078-5082.

25. Tatum JH, Shaw PE, Berry RE (1969) Degradation products from ascorbic acid Journal of Agricultural and Food Chemistry 17: 38-40.

26. Bajaj S, Singla D, Sakhuja N (2012) Stability Testing of Pharmaceutical Products. Journal of Applied Pharmaceutical Science 02: 129-138

27. Food and Drug Administration (2015) FDA Guidance for Industry, Analytica Procedures and Methods Validation: Chemistry, Manufacturing, and Controls Documentation, Draft Guidance.

28. Smart R, Spooner DF (1971) Microbiological spoilage in pharmaceuticals and cosmetics. J Soc Cosmet Chem 23: 721-773.

29. Hugbo PG, Onyekweli AO, Igwe I (2005) Microbial contamination and preservative capacity of some brands of cosmetic creams. Tropical Journal of Pharmaceutical Research 2: 229-234.

30. Gallarate M, Carlotti ME, Trotta M, Bovo S (1999) On the stability of ascorbic acid in emulsified systems for topical and cosmetic use. Int J Pharm 188: 233 241.

31. Marfil PHM, Santos EM, Telis VRN (2008) Ascorbic acid degradation kinetics in tomatoes at different drying conditions. LWT-Food Science and Technology 41 : 1642-1647.

32. Špiclin $P$, Gašperlin $M, K$ metec $V$ (2001) Stability of ascorbyl palmitate in topical microemulsions. Int J Pharm 222: 271-279.

33. Sheraz MA, Khan MF, Ahmed S, Kazi SH, Khattak SR, et al. (2014) Factors affecting formulation characteristics and stability of ascorbic acid in water-in-oil creams. Int J Cosmet Sci 36: 494-504.

34. Ahmad I, Sheraz MA, Ahmed S, Shaikh RH, Vaid FH, et al. (2011) Photostability and interaction of ascorbic acid in cream formulations. AAPS Pharm Sci Tech 12: $917-923$

35. Ahmad I, Ali Sheraz M, Ahmed S, Shad Z, Vaid FH (2012) Photostabilization of ascorbic acid with citric acid, tartaric acid and boric acid in cream formulations. Int J Cosmet Sci 34: 240-245. 